\title{
Distribution and Abundance of Parthenium hysterophorus L. in Metekel Zone, Northwest Ethiopia
}

\author{
Jemal Tola Horo*, Tesfaye Gudisa, Emebet Worku, Derese Tilahun \\ Ethiopian Institute of Agricultural Research (EIAR), Pawe Research Center, Pawe, Ethiopia \\ Email: ^tolajemal@gmail.com
}

How to cite this paper: Horo, J.T., Gudisa, T., Worku, E. and Tilahun, D. (2020) Distribution and Abundance of Parthenium hysterophorus L. in Metekel Zone, Northwest Ethiopia. American Journal of Plant Sciences, 11, 1101-1110.

https://doi.org/10.4236/ajps.2020.117078

Received: June 11, 2020

Accepted: July 17, 2020

Published: July 20, 2020

Copyright $\odot 2020$ by author(s) and Scientific Research Publishing Inc. This work is licensed under the Creative Commons Attribution International License (CC BY 4.0).

http://creativecommons.org/licenses/by/4.0/

\begin{abstract}
Parthenium hysterophorus $\mathrm{L}$. is a harmful invasive weed to plant biodiversity and human health. It is native to American tropics and first introduced to Ethiopia in the 1970s. Today, it is widely distributed across the country and severely affecting the biodiversity, crop, and animal production in the country. In the Metekel Zone, there was no report on its distribution and impacts so far. Therefore, this study was aimed to assess the distribution and abundance of the plant in the zone. The distribution and abundance data of the weed were recorded at five $\mathrm{km}$ intervals following all accessible roads of the zone. The result reveals that $P$. hysterophorus $\mathrm{L}$. was less distributed in the area with a $4.95 \%$ frequency. However, it was found abundantly growing at roadsides, wastelands, around habitation, market place, and around Zeghibridge where it can rapidly spread to most economical lands like the arable and grazing lands. Moreover, it has aggressively invaded a nursery site, which enables the weed to enter agricultural fields directly. This suggests that the weed is on a fast move to agricultural lands in the zone. The regular active development activities such as agricultural investment, construction of roads, and factories are presumed to promote its spread. Therefore, a decisive and timely decision is needed to mitigate the weed when it is still sparse and small.
\end{abstract}

\section{Keywords}

Parthenium hysterophorus L., Invasive Weed, Weed Control, Agricultural Fields, Arable Lands, Grazing Lands, Metekel Zone

\section{Introduction}

Parthenium hysterophorus $\mathrm{L}$. is of great concern among the invasive alien plant 
species (IAPS) identified in Ethiopia. It causes several ecological and agricultural problems, such as the loss of crop productivity, fodder scarcity, biodiversity depletion, and health problems to human beings and livestock [1] [2] [3]. Based on its impact on food production, plant biodiversity, and animal and human health, it is ranked number one before Prosopis juliflora, which is aggressively invading most grazing lands and arable lands in the Northeastern part of Ethiopia [4] [5]. Though cattle do not eat Parthenium, its effects were observed on them when they walk-by or graze through patches of this weed. Such animals had inflamed udder and subsequently suffered from fever and rashes [6]. The plant also negatively affects foraging behavior and flower visitation by bees (Apis mellifera) [7].

First introduced in the 1970s, it has rapidly invaded diverse habitats, including roadside, grassland, and crop fields in the central, eastern, and northern Ethiopia [8] [9] [10]. Recent investigations showed that the weed has already conquered the arable and grasslands, mainly in East Shewa, West Shewa, Arsi, and the other fertile zones in Oromia Regional states [11] [12]. At present, the weed has already established itself in almost every region of the country [3] [11] [13] [14].

So far, there is no recommended effective control method for this menacing weed other than cultural control such as hand hoeing and slashing/chopping before flowering. The nature of proliferation, strong reproductive potential, and wide ecological range of adaptation makes the eradication of Parthenium challenging [15]. Previously, the use of physical and chemical control methods had proved ineffective, expensive, and not eco-friendly. Since the weed has great regeneration potential, its control using biological agents like beetles (Zygogramma bicolorata, moth (Epiblema strenuana and Carmentaithacae), weevil ( $L i$ stronotus setosipennis), and leaf rust (Puccinia melampodi) have resulted in little success. Burning is effective in destroying the whole part of the plant but not recommended as it deteriorates the soil quality. Even though prolonged contacts with Parthenium plant can cause skin itching and dermatitis, hand hoeing proved to be more efficient than the use of herbicide [16]. However, it could be laborious to apply when the weed covers large areas. Thus, preventing the distribution and establishment of the weed from a new area is crucial.

In Metekel Zone (MZ), even though some scholars have reported its presence [10] [17] there was no report of severe invasion of Parthenium on agricultural lands up to date. Despite having fertile and virgin land, which is enormously suitable for crop and animal production, MZ had been less disturbed by cultivation compared to the northern and eastern parts of the country. However, recently, cultivation is dramatically increasing as the improved infrastructure and development attracted more investors to the area. This situation, coupled with persisting climate change, would probably stimulate the invasion of Parthenium on most economical lands such as arable and grazing lands.

In this study, we assessed the distribution and abundance of a fearsome Parthenium weed in MZ of Benishangul Gumuz region, Northwest Ethiopia. The actual means of its distribution in the zone were also investigated. 


\section{Material and Methods}

\subsection{Characterization of the Study Area}

Metekel Zone is positioned between $9.9^{\circ}$ to $12.5^{\circ}$ North latitude and $34.9^{\circ}$ to $36.6^{\circ}$ East longitude in Benishangul Gumuz Regional State, Ethiopia. It has seven administrative districts, namely; Pawe, Mandura, Dangur, Dibate, Bulen, Wembera, and Guba (Figure 1). With 3,387,817 hectares of an estimated total area, the zone is classified as Kolla (82\%), Woinadega (10\%), and Dega (8\%) agro-ecological zones. The altitude of the zone ranges from 600 meters to 3131 m.a.s.l. at Belaya Mountain and annually receives $1574 \mathrm{~mm}$ average rainfall (Pawe metrology record, 2014).
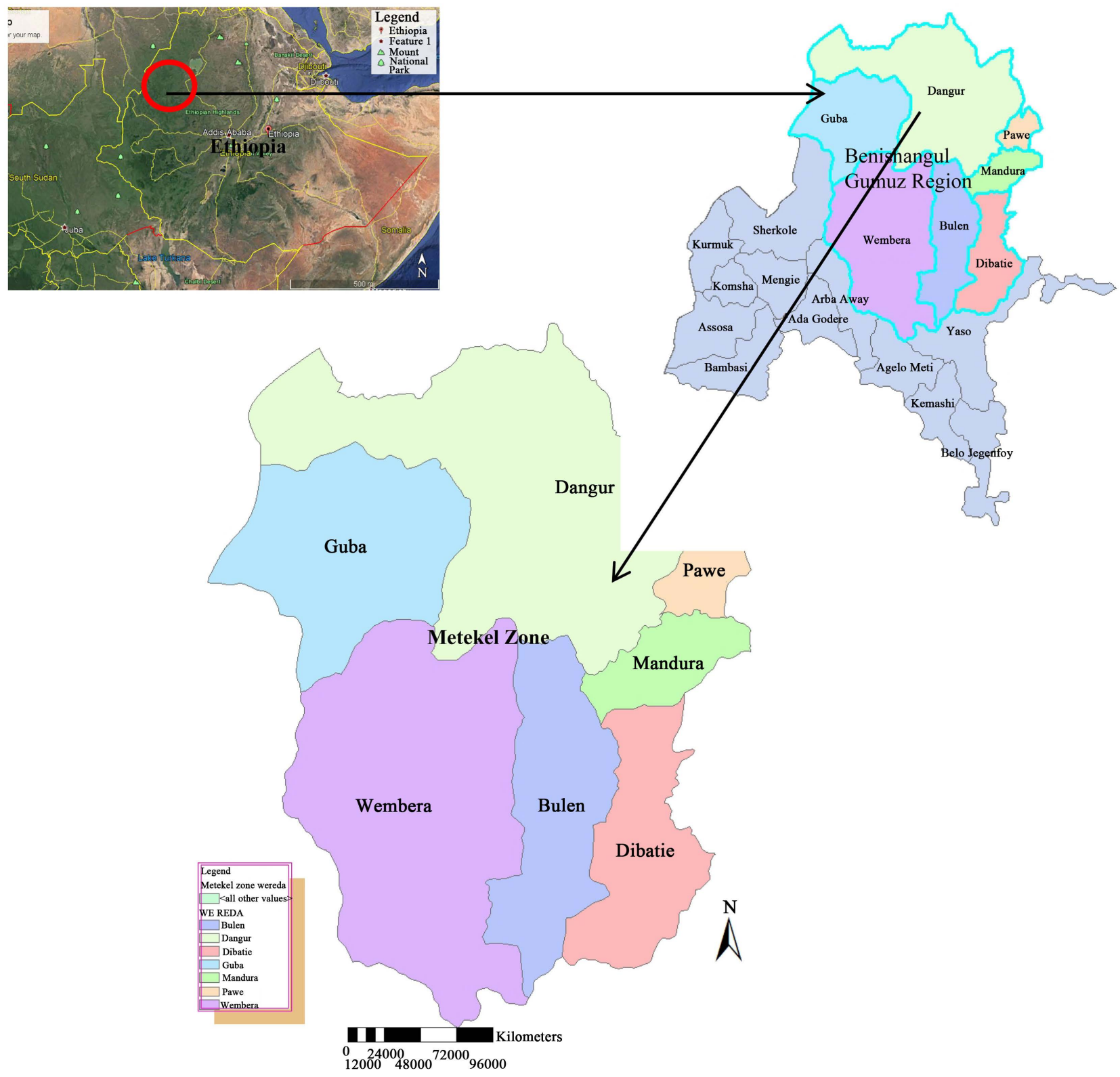

Figure 1. A map of the study area. Source: This study. 
According to the 2007 census of the central statistical agency of Ethiopia, the zone had a total population of 276,367 (137,248 female, and 139,119 male) of whom $86.39 \%$ were rural dwellers and dependent on agriculture. The grain crops produced in the area consists maize, sorghum, finger millet, rice, haricot bean, soya beans, groundnuts, and sesame with the highest area coverage by finger millet (19.7\%) followed by maize (12.8\%) and sorghum (12.3\%) [18]. Cattle, goats, and sheep are among the dominant animals reared in the Zone [19].

\subsection{Survey on the Distribution and Abundance P. hysterophorus in MZ}

The survey was conducted in the cropping season of 2016 in six Districts (i.e., Pawe, Mandura, Dibate, Bulen, Dangur, and Guba) of the MZ, Benishangul Gumuz regional state. Parthenium weed abundance was recorded at five $\mathrm{km}$ interval following all the accessible roads in the zone. The abundance was recorded based on researchers' observational judgment [20], and the waypoints were simultaneously recorded using hand-held GPS60. At each stop, all habitats such as roadside, rangeland, cropland, and wasteland were assessed in a certain radius. The estimation of $P$. hysterophorus was recorded using seven abundance level; "Absent"-if there was no P. hysterophorus, "Present"-abundance uncertain, "Rare"-if there were one sighting of one or a few plants, "Occasional"-if there were a few sightings of one or a few plants, "Frequent"-if there were many sightings of single plants or small groups, "Abundant"-if there were many clumps or stands, and "Very abundant" - if the area was covered by extensive stands. Besides, the existing potential means of spread for the weed were recorded.

\subsection{Data Analysis}

The abundance and distribution map of Parthenium weed was developed using ArcGIS version 10 (ESRI) (Figure 2) after waypoints, and abundance data were loaded on a computer and adjusted to readable format on Microsoft Excel.

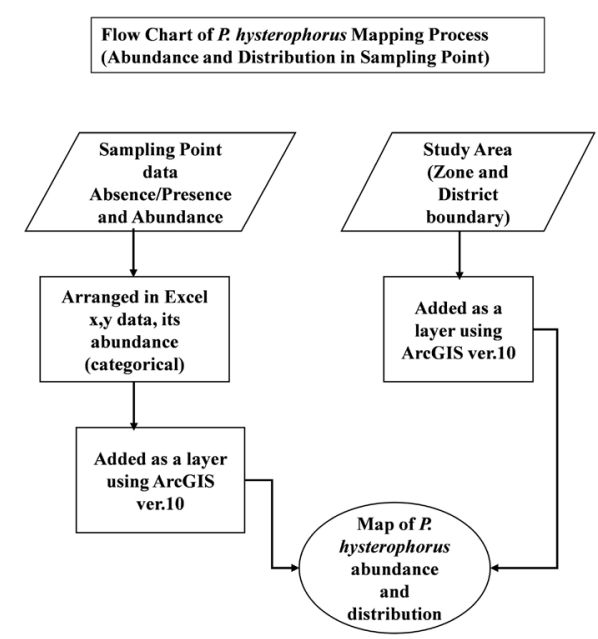

Figure 2. Flow chart of mapping process. 


\section{Results}

\subsection{Distribution and Abundance $P$. hysterophorus in MZ}

Parthenium was recorded on five (5) sampling points out of the total 101 sampling points taken across all the assessed areas of the zone with a $4.5 \%$ frequency (Figure 3). It aggressively invaded roadside, wastelands, around habitation, and market places in the Gilgel Beles, Almu ("Adare temertbet"), Dibate and Bulen cities (Table 1). Furthermore, robust individuals of the plant were found scattered in the field nearby the Zeghibridge of the river bordering Dibate and Bulen district. This is might be a sensitive place for easy spread of the weed. On top of this, the weed was aggressively invading the nursery site of Mandura district located at Gilgel Beles city (Figure 4).

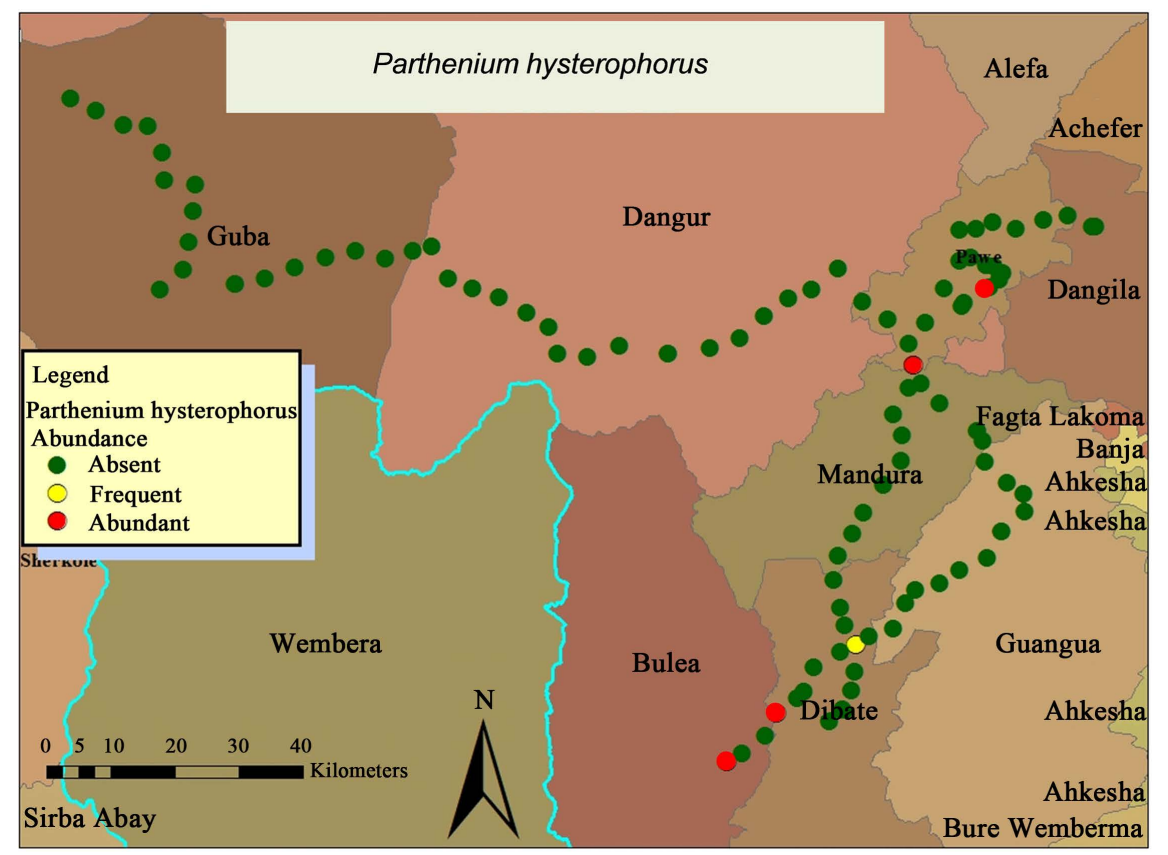

Figure 3. The distribution and abundance map of P. hysterophorus L. in MZ, Northwest Ethiopia.

Table 1. The status of $P$. hysterophorus distribution and abundance in MZ.

\begin{tabular}{ccccc}
\hline District & Present/Absence & Frequency (\%) & Abundance of Parthenium & Invaded habitats \\
\hline Pawe & + & 0.99 & Abundant & Wl \& Ah \\
Mandura & + & 0.99 & Abundant & Rs, Wl, Ah \& Ns \\
Dibate & + & 1.98 & Frequent & Rs \\
& + & & Abundant & Wl, \& Ab \\
Bulen & + & 0.99 & Abundant & Wl and Mp \\
Dangur & - & 0 & - & - \\
Guba & - & 0 & - & - \\
\hline
\end{tabular}

${ }^{*}$ Wl-Wastelands, Ah-Around habitation, Rs-Roadsides, Ns-Nursery site, Ab-Around bridge and Mp-Market places. 


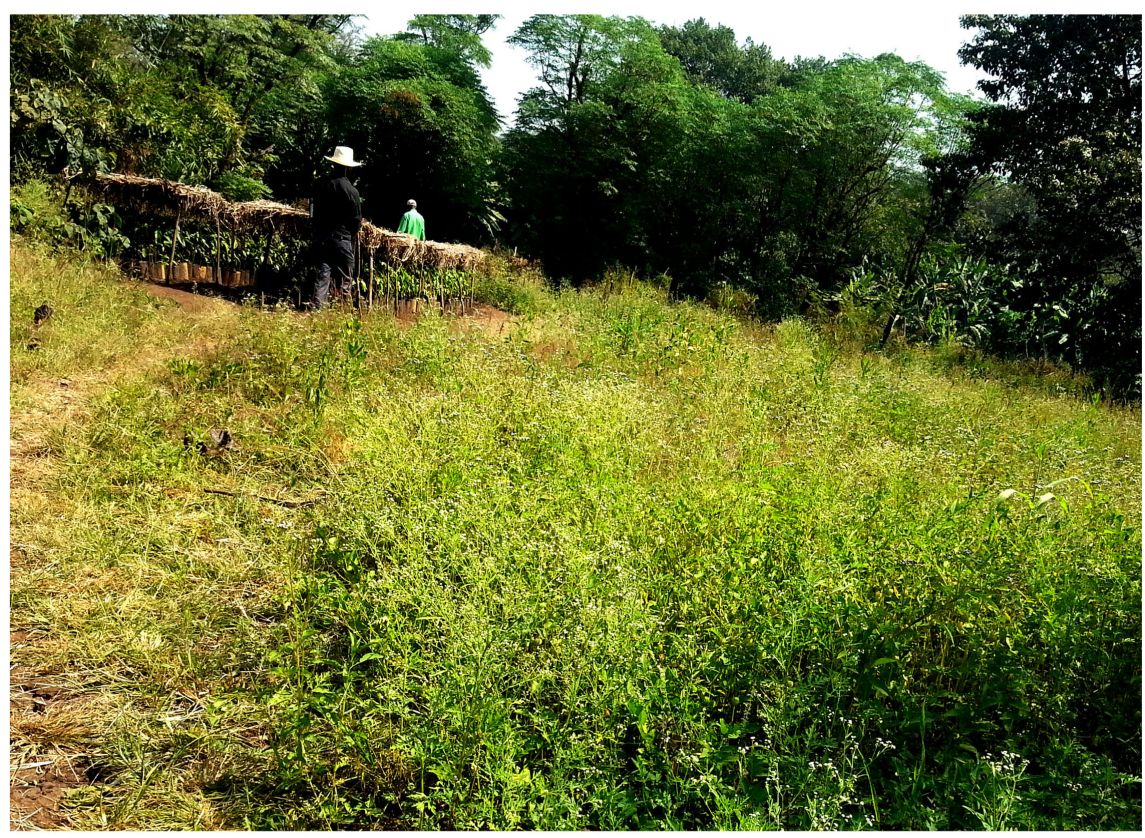

(a)

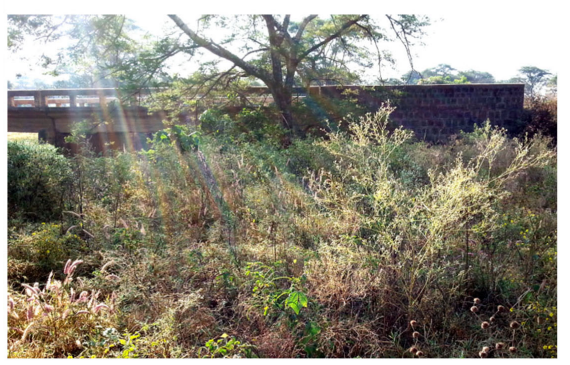

(b)

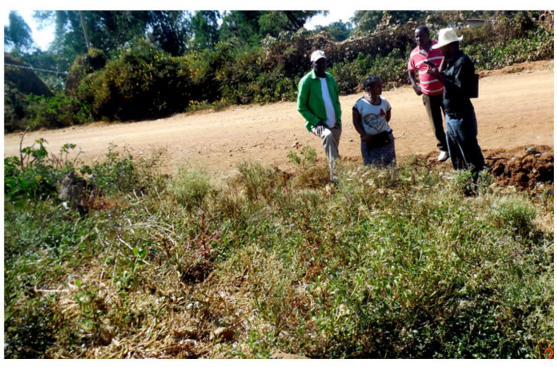

(c)

Figure 4. P. hyterophorus invasion in MZ. (a) Invasion of the Mandura District nursery site in the Gelgel Beles city, (b) Invasion near the Zeghi bridge, (c) Invasion on the roadside in the Dibate city.

\subsection{Means of Spread for P. hysterophorus in MZ}

The potential means of spread for P. hysterophorus in MZ includes road construction, vehicles, animals, rivers/irrigation water, and fruit/forest seedlings at Parthenium infected at nursery. Due to the Grand Ethiopian Renaissance Dum and Beles Sugar factory, there was a massive road construction extending from Chagni to Mandura through Dangur and Mandura through Jawi (Figure 5(a)). Thus, construction vehicles have crossed several agricultural fields, searching for soils and stones for the work. These vehicles were likely to distribute the weed from cities to rural areas. Besides, the highly populated animals in the zone contribute to the spread of the weed while feeding the infested field (Figure 5(c)). Above all, Mandura district, in collaboration with the zone agricultural office, was growing a grafted mango and other forestry seedlings at highly infested nursery with $P$. hysterophorus (Personal communication with expertise and observation, Figure 4(a)). 


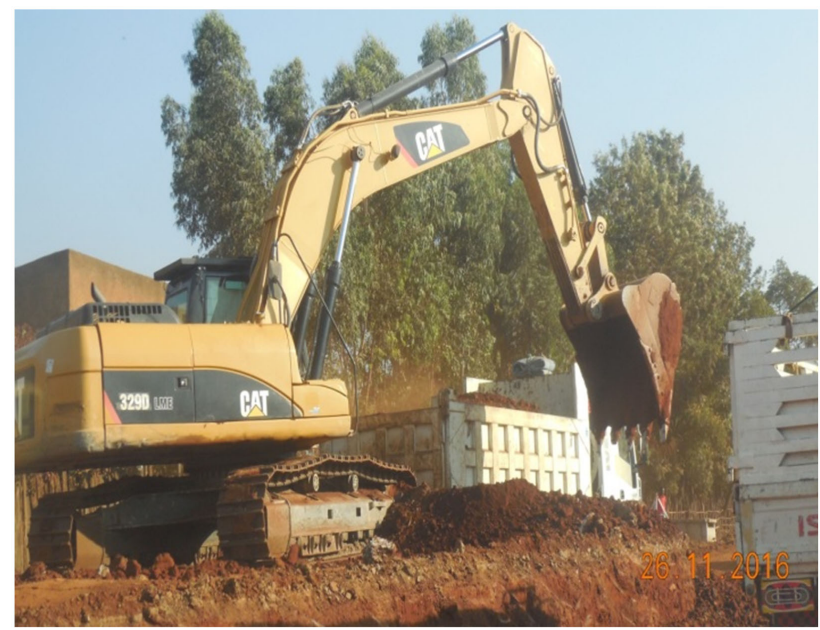

(a)

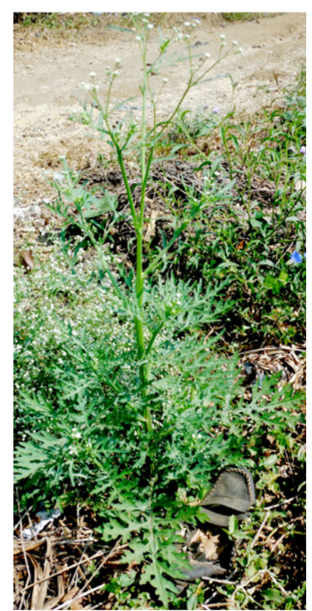

(b)

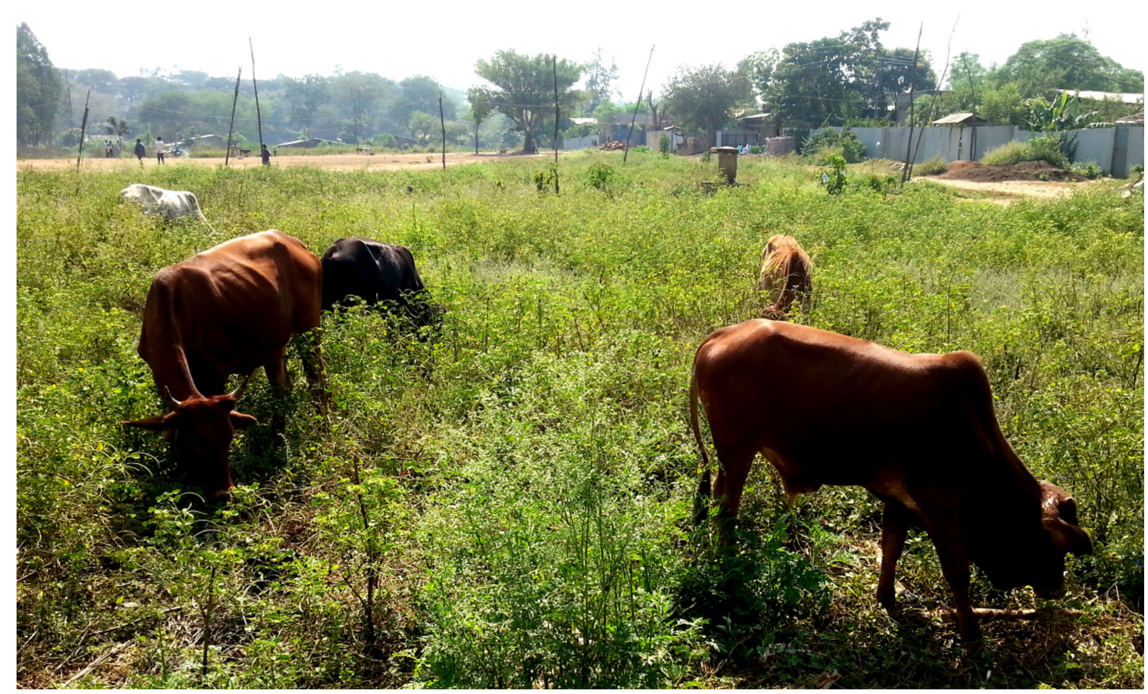

(c)

Figure 5. Means of transportation for deadly weed persisting in the region. (a) A contraction vehicle-pictured by the time of the survey on the way Chagni to Mandura district. (b) A Parthenium weed plant found growing at waste land near to the road in Gilgel Beles city. (c) Cattle feeding in the waste land infested with Parthenium weed at Gilgel Beles city. As Parthenium is unpalatable to animal they did not eat it, except the grasses.

\section{Discussion}

According to the present study, the P. hysterophorus was less distributed in MZ but aggressively invaded roadsides, wastelands, around habitation, and market places in four cities (i.e. Gilgel Beles, Dibate, Bulan and Almu "Adare temertbet"). Similarly, many scholars have reported that $P$. hysterophorus and other IAPS usually invade wasteland and roadsides in the cities at the phase of introduction [10] [11] [12]. The reason why they always appear in the city, and roadside is that their introduction is highly related to human activity [3]. After establishment, they eventually start moving to the most economically important areas like crop fields and grazing land. Vehicles, livestock, and road construction play 
a significant role in spreading the $P$. hysterophorus in particular [9] and other IAPS in general. Habitats that had continually disturbed and have low diversity become extremely vulnerable to the invasion [3].

Mosissa and colleagues [17] have surveyed in 2010 and reported five invasive alien plant species (i.e. Senna obtisifolia, Senna didymobotrya, Hyptis suaveolens, Lantana camera, and Parthenium hysterophorus) in MZ. According to their report, the distribution of $P$. hysterophorus was limited to roadsides, rural villages, and urban areas with less abundance while all other IAPS had already interred to agricultural fields. However, the current investigation confirmed that the coverage of $P$. hysterophorus was more abundant in the cities. It is alert that the weed has already established itself and ready to move to agricultural fields such as the arable and grazing lands.

Furthermore, the weed has started spreading from the area surrounding the Zeghibridge to the adjacent cropland and pasture on both sides of the river. In this particular study, there was no way to know when and how the plant was first introduced to the place; however, we speculated that the weed might have introduced with sand and stones used for the construction/maintenance of the bridge.

Moreover, the presence of $P$. hysterophorus at the nursery site most likely speeds up its spread across the area. It should be noted that raising seedlings at the place infested with $P$. hysterophorus is like providing transportation to agricultural fields. This way, the weed will not only infest crop fields but also be able to travel long distances and cover large areas relatively within a short period.

In general, $P$. hysterophorus is on the fast move to agricultural fields in the MZ. The crop and livestock production in the area has been already constrained by many factors like lack of agricultural technologies, disease and pests' pressure, and low production awareness of farmers. Thus, the invasion of Parthenium in agricultural fields, coupled with the existing problems, can be devastating and causes food insecurity. Therefore, the public administrators and policymakers of the regional government, in collaboration with all stakeholders, should take a decisive and timely decision to mitigate the weed when it is still sparse and small.

\section{Limitation}

This study was limited to accessible roads in the zone with a certain radius at each waypoint.

\section{Acknowledgements}

We are grateful to the management members and expertise of Agricultural and Natural Resource office of Metekel Zone for their unreserved support during the implementation of the study.

\section{Funding}

The study was financially supported by Ethiopian Institute of Agricultural Re- 
search under the budget code 1.6.4 of Crop Research.

\section{Conflicts of Interest}

The authors declare no conflicts of interest regarding the publication of this paper.

\section{References}

[1] Belayneh, B. (2018) Distribution and Socio-Economic Impacts of Invasive Alien Plant Species in Ethiopia: A Review. Open Journal of Plant Science, 2, 26-33. https://doi.org/10.17352/ojps.000012

[2] Kumar Rai, P. and Singh, J.S. (2020) Invasive Alien Plant Species: Their Impact on Environment, Ecosystem Services and Human Health. Ecological Indicators, 111, Article ID: 106020. https://doi.org/10.1016/j.ecolind.2019.106020

[3] Shiferaw, W., Demissew, S. and Bekele, T. (2018) Invasive Alien Plant Species in Ethiopia: Ecological Impacts on Biodiversity a Review Paper. International Journal of Molecular Biology, 3, 169-176. https://doi.org/10.15406/ijmboa.2018.03.00072

[4] Ahmed, M. and Rezene, F. (2020) Original Research Article Assessment on the Distribution and Spread of Invasive Alien Plant Species: The Case of Zone 1 and 3 of the Afar Region, Ethiopia. Journal of Research in Weed Science, 3, 101-119. https://doi.org/10.26655/JRWEEDSCI.2020.1.10

[5] Bufebo, B. and Elias, E. (2018) Distribution and Socio-Economic Impacts of Invasive Alien Plant Species in Ethiopia: A Review. Open Journal of Plant Science, 3, 26-33. https://doi.org/10.17352/ojps. 000012

[6] TNAU (2016) Parthenium on Livestock Health. http://agritech.tnau.ac.in/agriculture/agri_weedmgt_parthenium_livestock.html

[7] Ojija, F., Arnold, S.E.J. and Treydte, A.C. (2019) Impacts of Alien Invasive Parthenium hysterophorus on Flower Visitation by Insects to Co-Flowering Plants. Arthropod-Plant Interactions, 13, 719-734. https://doi.org/10.1007/s11829-019-09701-3

[8] Beyene, H. and Tessema, T. (2015) Distribution, Abundance, and Socio-Economic Impacts of Parthenium (Parthenium hysterophorus) in Southern Zone of Tigray, Ethiopia. Journal of Poverty, Investment and Development, 19, 22-29.

[9] Tamado, T. and Milberg, P. (2000) Weed Flora in Arable Fields of Eastern Ethiopia with Emphasis on the Occurrence of Parthenium hysterophorus. Weed Research, 40, 507-521. https://doi.org/10.1046/j.1365-3180.2000.00208.x

[10] Tessema, T., Wiesner, M. and Crops, O. (2011) Parthenium Weed (Parthenium hysterophorus L.) Research in Ethiopia: Impacts on Food Production, Plant Biodiversity and Human Health. Ethiopian Journal of Agricultural Sciences, 21, 128-150.

[11] Amare, F., Taye, T. and Niguse, H. (2017) Distribution and Abundance of Emerging Invasive Weeds in Central Western Part of Ethiopia. African Journal of Agricultural Research, 12, 1121-1127. https://doi.org/10.5897/AJAR2016.11922

[12] Hundessa, N. and Belachew, K. (2017) Socio-Economic Impacts of Parthenium hysterophorus $\mathrm{L}$. in East Shewa and West Arsi Zones of Ethiopia. International Journal of Agricultural Research, Innovation and Technology, 6, 5-11.

https://doi.org/10.3329/ijarit.v6i2.31696

[13] Jemal, T. and Taye, T. (2015) Abundance and Distribution of Invasive Alien Plant Species in Illu Ababora Zone of Oromia National Regional State, Ethiopia. Journal of Agricultural Science and Food Technology, 1, 94-100. 
[14] Fite, T. (2017) Distribution and Spread of Parthenium Weed [Parthenium hysterophorus L.) Infestation in Western Oromiya, Ethiopia. Agricultural Research and Technology: Open Access Journal, 11, Article ID: 555818. https://doi.org/10.19080/ARTOAJ.2017.11.555818

[15] Patel, S. (2011) Harmful and Beneficial Aspects of Parthenium hysterophorus: An Update. 3 Biotech, 1, 1-9. https://doi.org/10.1007/s13205-011-0007-7

[16] Tamado, T. and Milberg, P. (2004) Control of Parthenium (Parthenium hysterophorus) in Grain Sorghum (Sorghum bicolor) in the Smallholder Farming System in Eastern Ethiopia. Weed Technology, 18, 100-105. https://doi.org/10.1614/WT-03-033R

[17] Mosissa, D., Agajie, M., Reda, D. and Kefiyalew, A. (2018) Status and Impact of Newly Invading Alien Plant Species in Metekel Zone, Benishangul Gumuz Regional State Northwest of Ethiopia. International Journal of Plant Biology \& Research, 6, 1107.

[18] Birhanu, A., Mulugeta, A., Yalew, M., Adane, M., Fitsum, M. and Abebaw, A. (2017) What Partnership in Agricultural Technology Pre-Scaling Up Has Brought about for Agricultural Development: Evidence from North Western Ethiopia. Journal of Economics and Sustainable Development, 8, 6-11.

[19] Altaye, S.Z., Kassa, B., Agza, B., Alemu, F. and Muleta, G. (2014) Smallholder Cattle Production Systems in Metekel Zone, Northwest Ethiopia. Research Journal of Agriculture and Environmental Management, 3, 151-157.

[20] Wittenberg, R. (2004) Instruments and Tools for Assessing the Impact of Invasive Plant Species in Africa. Report Submitted under the PDF-B Phase of the UNEP/GEF Project: Removing Barriers to Invasive Plant Management in Africa. CABI Africa Regional Centre, Nairobi. 